\title{
BMJ Open Continuous glucose monitoring in older people with diabetes and memory problems: a mixed-methods feasibility study in the UK
}

\author{
Katharina Mattishent (D , ${ }^{1}$ Kathleen Lane, ${ }^{1}$ Charlotte Salter, ${ }^{1}$ Ketan Dhatariya,${ }^{2}$ \\ Helen M May, ${ }^{3}$ Sankalpa Neupane, ${ }^{2}$ Yoon K Loke ${ }^{1}$
}

To cite: Mattishent K, Lane K, Salter C, et al. Continuous glucose monitoring in older people with diabetes and memory problems: a mixed-methods feasibility study in the UK. BMJ Open 2019;9:e032037. doi:10.1136/ bmjopen-2019-032037

- Prepublication history and additional material for this paper are available online. To view these files, please visit the journal online (http://dx.doi. org/10.1136bmjopen-2019032037).

Received 04 June 2019 Revised 03 September 2019 Accepted 04 0ctober 2019

D) Check for updates

(C) Author(s) (or their employer(s)) 2019. Re-use permitted under CC BY-NC. No commercial re-use. See rights and permissions. Published by BMJ.

${ }^{1}$ Norwich Medical School, University of East Anglia, Norwich, UK

${ }^{2}$ Elsie Bertram Diabetes Centre, Norfolk and Norwich University Hospitals NHS Foundation Trust, Norwich, Norfolk, UK

${ }^{3}$ Older People's Medicine,

Norfolk and Norwich University Hospitals NHS Foundation Trust, Norwich, Norfolk, UK

Correspondence to Dr Katharina Mattishent; k.mattishent@uea.ac.uk

\section{ABSTRACT}

Objectives Older people with diabetes are at increased risk of harm from hypoglycaemia, particularly where there are coexisting memory problems. Continuous glucose monitoring (CGM) offers important benefits in terms of detecting hypoglycaemia, but the feasibility of use and extent of data capture has not been tested in this patient group. Our objective was to investigate the feasibility of trialling a CGM intervention in the community setting in older people with diabetes and memory problems.

Design Mixed-methods feasibility study.

Setting Community dwellings in the UK.

Participants Patients aged $\geq 65$ with diabetes and abbreviated mental test score $\leq 8$ or known dementia. Intervention FreeStyle Libre CGM.

Primary and secondary outcome measures Feasibility criteria were numbers of eligible patients, recruitment, attrition, extent of capture of glucose readings and adverse events. Qualitative interview.

Results We identified 49 eligible participants; 17 consented, but 5 withdrew before recording of data because they or their carers felt unable to manage study procedures. 12 participants (mean age 85 years) completed the study without adverse events. Data capture across 14 days ranged between $3 \%$ and $92 \%$ (mean $55 \%$ ); 6 participants had $<60 \%$ capture. Hypoglycaemic events were recorded in six out of nine insulin users. Qualitative interviews found: the device does not interfere with daily activities, usability and comfort was positive, and it was helpful for carers in monitoring participants' glucose concentrations.

Conclusions The device was acceptable to participants, and carers reported greater ease in monitoring the participant's glucose concentrations. However, completeness of data capture varied considerably with this device due to the need for users to conduct $\geq 3$ scans per day. Real-time devices with automated data transfer may be more suitable in older people with memory problems.

\section{INTRODUCTION}

It is estimated that $13 \%-20 \%$ of older people with dementia also have coexisting diabetes. ${ }^{1}$ Over the coming decades, this will pose a significant healthcare burden, especially in a worldwide expectation that by
Strengths and limitations of this study

- This is a community-based study focussing on older people with memory problems and diabetes.

- We used a mixed-methods approach exploring both participants' and carers' experiences using a continuous glucose monitoring (CGM) device.

- Feasibility criteria included recruitment and retention, data capture with the CGM device, in addition acceptability of the device.

- The study monitoring period was only 2 weeks, which does not fully reflect longer term use of the device.

- The CGM device used in this study is known to have less accuracy at extremes of glucose values.

2045, 629 million people with be living with diabetes $^{2}$ and 125 million people will be living with dementia by $2050 .^{3}$

Self-management of diabetes is particularly challenging for older patients, because they may have limited recall of the dangers of hypoglycaemia and what remedial action to take, ${ }^{4}$ and because they are more prone to hypoglycaemia from their medication. ${ }^{5}{ }^{6}$ Evidence from a recent meta-analysis reports that patients with diabetes and dementia may be even more susceptible to hypoglycaemia and subsequent cognitive complications. ${ }^{7} \mathrm{~A}$ cohort study using registry data from German and Austrian diabetes centres found that older people with diabetes and coexisting dementia had higher rates of severe hypoglycaemia (requiring third party assistance) and hypoglycaemia with coma compared with patients without dementia. ${ }^{8}$ Hence, the adverse effects of hypoglycaemia may be of far more pressing concern to frail older people, rather than strict glycaemic targets for reduction of vascular complications.

In this vulnerable group, the healthcare system should consider different approaches 
for the monitoring of day to day glucose readings. Conventional methods, such as self-monitoring of blood glucose (SMBG), may not be appropriate in older people with memory problems, as they may not be able to recognise symptoms of changing blood sugars. Nocturnal and asymptomatic hypoglycaemia events are not reliably captured because SMBG only provides a snap shot of the glucose level at a single point in time where the user or carer has taken action to do fingerprick testing.

Newer technologies, such as continuous glucose monitoring (CGM), have gained momentum in the management of diabetes, in particular in children and younger adults. This is now accompanied by a rapidly growing interest towards research studies of CGM in older people. A systematic review of studies using CGM in older people found that hypoglycaemic episodes were occurring in $28 \%-65 \%$ of participants with most of those episodes $(80 \%)$ being asymptomatic. Some participants spent up to 2 hours per day in the hypoglycaemic range. The review reported that older people found CGM use to be acceptable, with potential improvements in healthrelated well-being. ${ }^{9}$

However, to date we are not aware of studies that have explored the views and experiences of both the participants and their carers regarding the use of CGM in older people with diabetes and coexisting memory problems. Hence, our objective was to investigate the feasibility of using flash-glucose monitoring (a version of CGM) in this patient group. Specifically, we investigated recruitment, retention and the extent to which we could capture glucose data. In addition, we asked participants (and their carers) about their experience of using of the device (including anxiety or inconvenience related to wearing the CGM sensor) and whether they experienced any adverse events (pain or skin reactions).

\section{METHODS}

Design

We used mixed methods to conduct a feasibility study of CGM in older people with diabetes and coexisting memory problems living in the community.

\section{Setting}

Data collection took place in the community and the device was only fitted after patients had been discharged from acute care. The participants were initially identified and recruited while an inpatient under the Older People's Medicine and/or Acute Medicine Departments at a University Hospital Trust in Norfolk, UK. We subsequently contacted the patients by telephone after their discharge from hospital to confirm their willingness to have the device fitted at their place of residence. Recruitment took place between 1 February 2018 and 31 January 2019.

\section{Sample size}

This feasibility study aimed to estimate the important parameters for the sample size calculation for a full trial; no sample size calculation has been undertaken at this stage. We aimed to recruit up to 20 participants. This is a size that the research team considered to be pragmatic and sufficient as indicative quantitative data on which to base the sample size for a full trial.

\section{Choice of device}

At commencement of this feasibility study, the CGM device (FreeStyle Libre) was licensed for use in children and adults and available direct to consumers via the internet or from pharmacies. The use of this device provides ambulatory glucose profiles, giving graphic and quantitative information on 24-hour glucose patterns. This information can be viewed on a computer using the manufacturer's software. It does not require finger-prick testing for calibration.

The system consists of a reader (although Android phones and certain ioS devices can download an app, which replaces the need for a reader) and a sensor (35 $\mathrm{mm} \times 5 \mathrm{~mm}$ ), which exchange data through Near Field Communication technology. The sensor is applied to the back of a person's arm. It is able to store blocks of glucose data spanning 8 hours and will function for 14 days. While glucose levels are measured continuously, data are not transmitted continuously from the sensor. Instead, the user has to swipe the sensor with a reader (hence the term 'flash glucose monitoring' used by the manufacturer) at 8 hourly intervals in order to achieve complete capture of data throughout the 2-week life-span of a sensor. If there is a gap of more than 8 hours between scans, then there will be missing data. For example, if there is a 10-hour gap between two scans, then there will be 2 hours of lost data.

The manufacturer of the device was not involved in the funding, the design or the interpretation of the study.

\section{Participants}

Eligible participants were 65 or older with type 1 or type 2 diabetes mellitus. They needed to be on glucose-lowering medication (not diet or Metformin only), have an abbreviated Mini-Mental Test (AMT) score equal or less than 8 (out of 10$)^{10}$ or already have a formal diagnosis of dementia. Use of the AMT is mandated as a screening tool for memory problems in the hospital policy.

The value of AMT in hospital settings was confirmed in a systematic review and meta-analysis on screening for dementia in general hospital inpatients, where AMT was reported to have good discriminant ability Area Under the Curve (AUC) 0.88. ${ }^{11}$

\section{Measurements}

Feasibility outcomes (quantitative)

We investigated eligibility, recruitment, retention, reasons for withdrawal, data capture and adverse events. For categorical variables, the number and percentage will be 


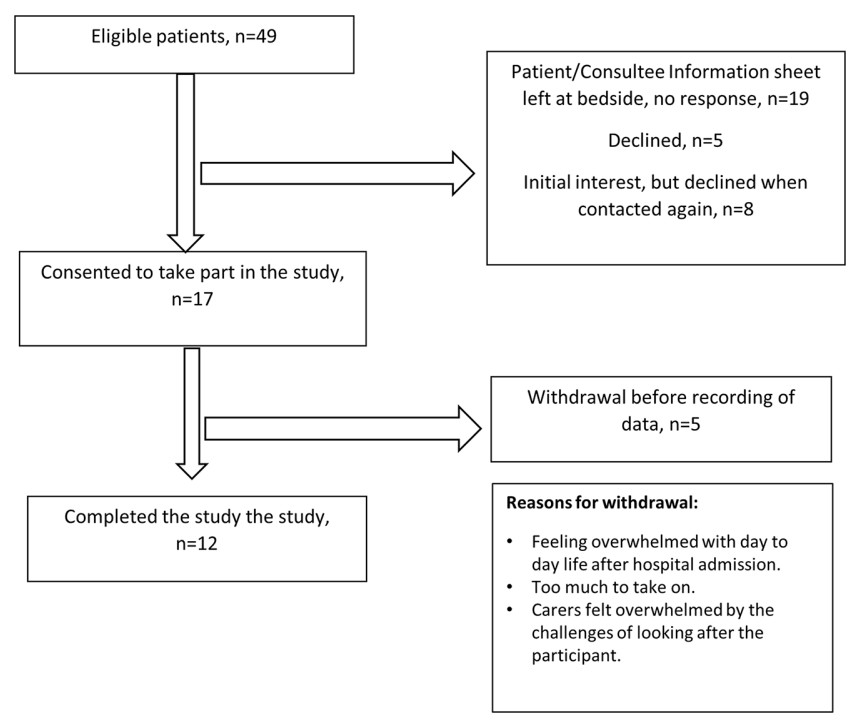

Figure 1 Patient recruitment flowchart.

presented. For continuous variables, the mean or median will be presented.

For measure of 'time in range', we set the reader to record it between $4 \mathrm{mmol} / \mathrm{L}$ to $10 \mathrm{mmol} / \mathrm{L}$, which is similar to expert recommendations. ${ }^{12} 13$

Participants were asked to continue with their usual diabetes management during the study period.

\section{Patient outcomes (qualitative)}

Semistructured face-to-face interviews took place after the participants had worn the device for 2 weeks. A topic guide was used (see online supplementary appendix 1) to ensure the same domains were covered in each interview. Participants and carers were encouraged to talk about their experiences using the device. Domains covered in the interview were acceptability of the device, exploration of expectations, effectiveness, including experience of scanning the device and immediate or longer-term consequences for the user and their diabetes management, consequences, including impact on wider health and well-being and overall opinion of the device. Detailed field notes were produced after each interview.

Thematic analysis was used, once the interviews had been transcribed. ${ }^{14}$ Familiarisation took place by listening to the interview recordings and reading of the transcripts.

Framework analysis was applied to order, chart and search the data manually and with software (NVivo 12, MS Word). To ensure rigour and trustworthiness, coding was undertaken by two members of the research team (KM and KL) and transcripts were checked for accuracy.

\section{RESULTS}

The patient recruitment flowchart is set out in figure 1 .

We identified 49 eligible participants. Seventeen people consented and 12 completed the study. During the inpatient stay, information sheets were left at the bedside when it was not possible to speak to potential consultees (in cases where a patient did not have capacity) or a potential participant did not to discuss the study at the time of visit, but wanted to read the information sheet.

The main reason for deciding not to participate after discharge home was that the participant or carer felt it was too much to take on. Participants living on their own were finding it challenging coping with day to day life. Carers felt overwhelmed by the challenges of looking after the participant.

Table 1 sets out baseline characteristics and data captured with the FreeStyle Libre device for participants who completed the study period. Twelve participants (mean age 85 years) completed the study without any adverse events (skin reactions and/or pain). All had type 2 diabetes apart form one participant with type 1 diabetes. Three participants had a formal diagnosis of dementia. The AMT for the nine participants who did not have a

Table 1 Baseline characteristics and data captured with FreeStyle Libre

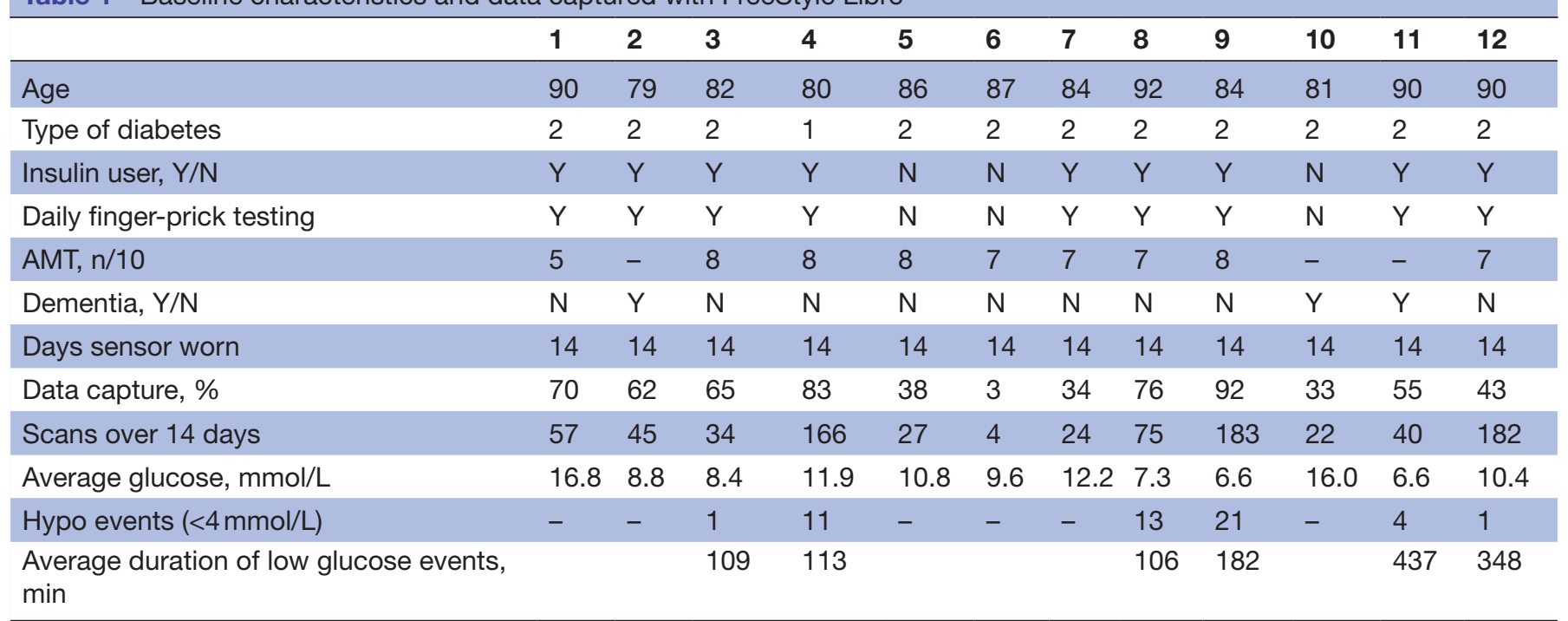

AMT, abbreviated Mini-Mental Test. 


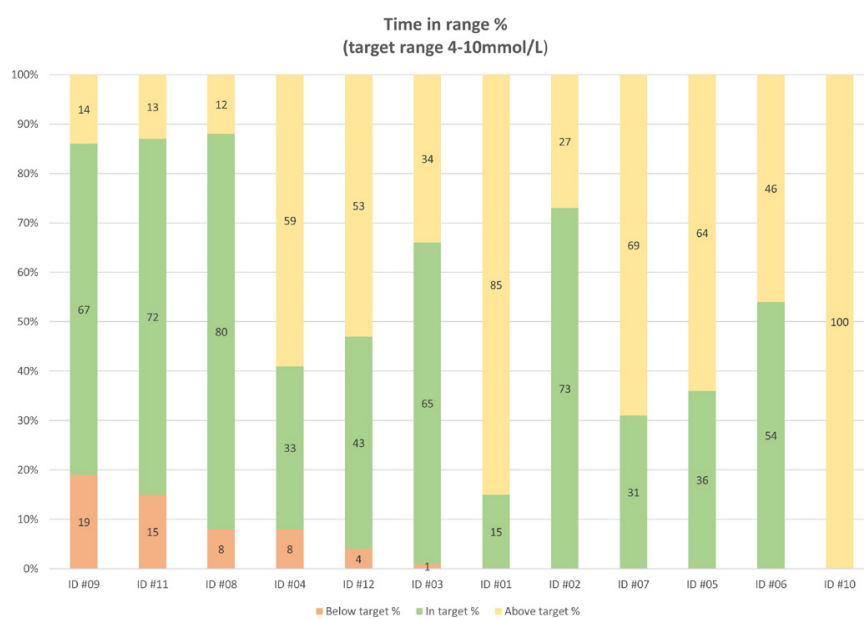

Figure 2 Time in range for each participant.

formal diagnosis of dementia ranged between 5 and 8 out of 10 .

Data capture across 14 days ranged between $3 \%$ and 92\% (mean 55\%); six participants had less than $60 \%$ capture. Nine participants were insulin users, of which six (66\%) experienced hypoglycaemic events (some prolonged). The average duration of hypoglycaemic events ranged from $106 \mathrm{~min}$ to $437 \mathrm{~min}$.

figure 2 depicts the time in range for each participant, including the proportions spent below and above the target range $(4-10 \mathrm{mmol} / \mathrm{L})$. Figure 2 shows those participants with hypoglycaemic episodes first, followed by the six participants who did not experience hypoglycaemic episodes. The percentage of time spent in the hypoglycaemic range is illustrated in red (below $4 \mathrm{mmol} / \mathrm{L}$ ), time spent in range in green $(4-10 \mathrm{mmol} / \mathrm{L})$ and time spent above range is illustrated in yellow (above $10 \mathrm{mmol} / \mathrm{L}$ ).

\section{Results from the interviews}

All participants (and, where applicable, carers) agreed to take part in the semistructured interview. The 12 interviews all took place in the participants' homes, apart from three. Two of those three were nursing home residents (IDs \#01 and \#12), and one participant (ID \#04) was in a community hospital for rehabilitation during the study period. The demographics of the participants who completed the study period are set out in table 2 . Analysis of the main findings is presented below under key domains including acceptability, expectations, effectiveness and consequences. Representative data extracts are presented verbatim (table 3 ) with all participant and carer identifiers removed and replaced by the participants' and carers' IDs.

\section{Acceptability}

Participants and carers overwhelmingly found using the device acceptable. Almost without exception participants reported the device was so unobtrusive that they did not know or were not conscious of wearing the device throughout the 2 weeks and that it did not interfere with day-to-day activities (table 3). In addition, participants
Table 2 Care arrangements of participants who completed the study period

\begin{tabular}{|c|c|c|}
\hline ID & Accommodation & $\begin{array}{l}\text { Social situation at time of } \\
\text { interview }\end{array}$ \\
\hline 01 & $\begin{array}{l}\text { Room in Nursing } \\
\text { Home }\end{array}$ & $\begin{array}{l}\text { Lives in nursing home, nurse } \\
\text { present at interview }\end{array}$ \\
\hline 02 & House & $\begin{array}{l}\text { Lives with spouse (present at } \\
\text { interview); package of care four } \\
\text { times per day }\end{array}$ \\
\hline 03 & Bungalow & $\begin{array}{l}\text { Lives with spouse (present at } \\
\text { interview who is main carer }\end{array}$ \\
\hline 04 & Bungalow & $\begin{array}{l}\text { In community hospital; spouse } \\
\text { present at interview }\end{array}$ \\
\hline 05 & Cottage & Lives alone, independent \\
\hline 06 & Bungalow & $\begin{array}{l}\text { Lives alone, cleaner, supportive } \\
\text { family }\end{array}$ \\
\hline 07 & House & Lives alone, daughter helps \\
\hline 08 & House & $\begin{array}{l}\text { Lives alone, package of care } \\
\text { three times per day }\end{array}$ \\
\hline 09 & Bungalow & $\begin{array}{l}\text { Lives with spouse (present at } \\
\text { interview) who is main carer }\end{array}$ \\
\hline 10 & House & $\begin{array}{l}\text { Lives with spouse (present at } \\
\text { interview) who is main carer }\end{array}$ \\
\hline 11 & House & $\begin{array}{l}\text { Lives with spouse (present at } \\
\text { interview) who is main carer }\end{array}$ \\
\hline 12 & $\begin{array}{l}\text { Room in Nursing } \\
\text { Home }\end{array}$ & Nursing home \\
\hline
\end{tabular}

confirmed that they were not aware of the device at night when they were sleeping.

Many participants described what they considered advantageous about the device. The most common example given was the elimination of finger-pricking. Participant \#07 described that their fingers got sore from doing finger prick tests.

\section{Exploration of expectations}

When asked about expectations they had about wearing the device, many participants stated that they had had none. Participants were also asked if any expectations had come to mind about what it meant for their diabetes: again, they replied they had none.

One participant revealed an altruistic motivation to his joining the study (see table 3 ). Carer \#11 also exhibited altruistic motivations when describing their expectations of being on the study, explaining that the findings will be positive for other people. ${ }^{15}$

Other expectations showed an interest in contributing to science and a natural curiosity of being part of a research study (table 3). For another participant, joining the study meant that they had an opportunity to join the 21st century' (participant \#04).

A distinct perspective was provided by the carer \#02they admitted wondering if this was 'a scam or something', 


\begin{tabular}{|c|c|}
\hline Theme & Illustrative quotes \\
\hline Acceptability & $\begin{array}{l}\text { 'I don’t even know it’s on’ (ID \#07); } \\
\text { 'Easy to take a reading' and 'it was silent and stayed in place' (ID \#10). }\end{array}$ \\
\hline $\begin{array}{l}\text { Exploration of } \\
\text { expectations }\end{array}$ & $\begin{array}{l}\text { 'What they do with it, they can do what they like with me' (ID \#01); } \\
\text { 'You've got to work with science and progress' (ID\#03); } \\
\text { 'I found out what it did and I thought, this is fantastic' (Carer ID \#02). }\end{array}$ \\
\hline Consequences & $\begin{array}{l}\text { '... when it was low and then when I then give him something, it had then gone up so I knew it was } \\
\text { working, so I was happy, more than happy with it. Yes, I felt happy and I felt safer.' (Carer ID \#11); } \\
\text { 'I just think it like I say with the whole package of the Alzheimer's and dementia he's not always } \\
\text { understanding and doesn't want it done and will pull his hand away and you know sometimes it's just } \\
\text { all too much' (Carer ID \#02). }\end{array}$ \\
\hline
\end{tabular}

but became reassured on hearing details about the device and the feasibility study (table 3).

\section{Effectiveness}

Interviews explored the experience of participants / carers using the device for 2 weeks and whether they felt they found any effectiveness for the user and their diabetes health. Participants/carers found using the device effective, some preferring it over SMBG.

Carers spoke favourably about the simplicity of the device, being 'handy at night-times' (carer \#02) for checking glucose levels without disturbing the participant and about the participant not being limited to the number of times they could check their glucose levels.

\section{Consequences}

The impact on participants' and carers' wider health and well-being was explored. In particular, we were interested whether they found any aspects of the experience positive or negative. This included their views on whether the device had an impact on their symptoms, their experiences of living with diabetes and coexisting memory problems and on their socialising and day-to-day activities.

Although no participant reported anxiety or stress in wearing the device, a few reported that they wondered about the different results obtained from the device compared with finger-pricking. Participant ID\#12 expressed disappointment that the readings from the device did not always match the readings from the finger prick test.

Carers found the device particularly useful as it made them feel reassured and safer being able to check glucose levels, without having to use SMBG. No reports of anxiety or stress in using the device were given by carers (table 3 ).

Another carer made the point of participant \#02 not always understanding the need for SMBG due to the underlying dementia (table 3 ).

One participant reported that wearing the device 'made them feel confident' and, now that the 2-week episode had ended, they would 'miss it ... it was a boon to have it' (participant \#013).

\section{Overall}

Participants were asked if they would recommend the device to others or what would they would say about their attitude to device to anyone who was considering it. They all responded positively about recommending the device.

One drawback mentioned was financial (table 3). Some participants remarked on discrepant readings provided by the device compared with finger-pricking. One participant was explicit that they would like the device 'to be more accurate', comparing its readings less favourably with finger-pricking the results of which, they said, set their mind 'more at rest' (participant \#09). Nevertheless, the overall view of the device remained positive.

\section{DISCUSSION}

This study has shown that while the participants found wearing the sensor acceptable, data capture varied, depending on how many times the reader was used to scan the sensor during the study period. This is in contrast to findings from Ruedy et al's study (a posthoc analysis of the multicentre DIAMOND trial) looking at the effectiveness of CGM in adults aged 60 years and older with type1 or type 2 diabetes using multiple daily insulin injections. The authors found that of the 61 participants in the CGM group completing the study, $97 \%$ used CGM six or more days per week at the 6-month follow-up. ${ }^{16}$

It should be noted though that these participants were not frail, and the inclusion criteria required a stable diabetes regime for 3 months prior to study entry, use of SMBG three or more times daily, with no history of recurrent hypoglycaemia. ${ }^{17}$

Our study illustrates the real-world difficulties that older people with memory problems and their carers face in glucose self-monitoring. We are aware of other 
studies using flash glucose monitoring in older people, but these have not reported on the extent of data capture. $^{18} 19$

Future studies should employ a CGM device that does not require participants to carry out an action (eg, swiping reader over sensor), in order to transfer data and obtain a reading. Nevertheless, some carers found it to be a useful and reassuring tool in managing this complex group of patients without having to resort to finger prick testing in a person who may not be able to understand the reasons for it.

Based on a recently published international consensus on clinical targets for CGM data interpretation, only 4 out of the 12 participants reached the target of $70 \%$ or more data capture in fourteen days. ${ }^{13}$ The consensus statement for CGM targets in older people is that they should spend more than $50 \%$ in the target range $(3.9-10 \mathrm{mmol} / \mathrm{L})$, less than $1 \%$ below the target range $(<3.9 \mathrm{mmol} / \mathrm{L})$ and less than $10 \%$ above target $(>13.9 \mathrm{mmol} / \mathrm{L})$. Of the six participants who experienced hypoglycaemic episodes during the 14 days of wearing the device, only one spent $1 \%$ below the target range. Six participants reached the above $50 \%$ time in range target.

Recruitment proved challenging in this vulnerable group, particularly because we chose to identify and recruit potential participants while they were inpatients in an acute hospital setting. Challenges arose when a potential participant lacked capacity and consultee information sheets were left with the patient. Often it was not possible to speak to next of kin, relatives or friends who could have been consultees, due to the unpredictability of visiting and some patients not being visited at all while in hospital. As a result, a group of potential participants did not get the opportunity to consider taking part in this study. In addition, it became apparent that on discharge some participants found getting back into a daily routine and coping with day-to-day life overwhelming and therefore decided to withdraw from the study, despite showing interest in principle.

Factors such as acute illness and the disorientating and stressful environment of being in hospital meant that potential participants were at times not in the best position to digest lots of information about taking part in the study. Following on from this, it would be advisable to try and recruit in the community via primary care, but the initial approach is still challenging as traditional methods (eg, sending out letters of invitation with reply slips) may not succeed.

Regarding retention, it became apparent that on discharge some participants (or their carers) found getting back into a daily routine and coping with day-to-day life overwhelming and therefore decided to withdraw from the study, despite showing interest in principle. Greater trial support (eg, research nurses) for participants and carers may help address this.

Our feasibility study demonstrates that subsequent larger trials must address the above challenges, in order to maximise recruitment, retention and data capture.

\section{Strengths and limitations}

Our study used a mixed-methods approach exploring participants' and carers' experiences during the study period.

With regard to the use of the AMT, we acknowledge that its use only covers three cognitive domains (memory, orientation, attention/calculation) and there are more rigorous cognitive tests available. The more rigorous tests do not necessarily lend themselves to being carried out in an acute busy hospital setting. ${ }^{20}$ Our feasibility study was not about making new dementia diagnoses. Rather, we wanted to identify inpatients with any memory problems (irrespective of the possible underlying pathology) during their hospital admission who might benefit from the use of CGM. We appreciate that differences in cognitive profiles may arise according to type of diabetes or other underlying psychological issues, but this does not change the need for a strategy of hypoglycaemia detection and minimisation.

With regard to the capture of hypoglycaemia, the manufacturer of FreeStyle Libre has reported their sensor may have less accuracy in the lower glucose ranges when compared with SMBG. A clinical study showed that $40 \%$ of the time when the device indicated an interstitial glucose level of less than $3.3 \mathrm{mmol} / \mathrm{L}$, the capillary reading was between $4.5 \mathrm{mmol} / \mathrm{L}$ and $8.9 \mathrm{mmol} / \mathrm{L}$. A further study carried out in France with older patients with type 2 diabetes (on insulin) in care homes, found that $51 \%$ of hypoglycaemic episodes captured with FreeStyle Libre were associated with values equal or greater than $3.9 \mathrm{mmol} / \mathrm{L}$ on capillary readings. ${ }^{18}$

Despite limitations of the FreeStyle Libre in hypoglycaemia capture, our findings are supported by two recent pieces of research. A conference abstract presented at Endo $2019^{19}$ (New Orleans 23-26 March 2019) on the exposure to hypoglycaemia in older adults with type 1 diabetes analysed blinded CGM (Dexcom G4 Platinum) data in over 200 older adults (median age 68years) collected at baseline in a randomised controlled trial, assessing the effect of CGM on hypoglycaemia. These older adults spend over 1 hour per day in the hypoglycaemic range and over $100 \mathrm{~min}$ per day in those with impaired hypoglycaemic awareness. ${ }^{19}$ In addition, a 2019 Japanese study investigated the use of blinded CGM (Medtronic iPro2) in older people in an outpatient setting in Japan. Out of 326 participants, 7 used CGM. Asymptomatic hypoglycaemic episodes occurred in five out of the seven CGM users. ${ }^{21}$

While our feasibility study took place within one area of the UK, we believe that the results are potentially generalisable to the rest of the older population in the UK with diabetes and memory problems. We believe that older people with memory problems anywhere in the world will face similar hurdles when using a new technological device. However, we had difficulty recruiting eligible participants who had severe dementia needing full-time residential care. Our findings cannot be generalised to this group. 


\section{Meaning of findings and potential for future work}

CGM has gained momentum in the last few years, with more affordable devices being freely available for people with diabetes to purchase. However, the focus has very much been on adults and children with type 1 diabetes and pregnant women. More recently, the National Health Service published its long-term plan, making reference to the fact that from April 2019, patients with type 1 diabetes benefit from flash glucose monitors ending the variation patients in some parts of the country are facing. ${ }^{22}$ While this is a very welcome development, there is a need to seriously think about older frail people (especially those on insulin and/or with memory problems) and how best to manage diabetes in later life focussing on avoidance of hypoglycaemia and its adverse effects. This will require an enormous shift in mindset by healthcare professionals and policy makers.

A key area for investigation is what type of CGM (ie, intermittent scanning/flash glucose monitoring, continuous transmission via Bluetooth or blinded and retrospective CGM) would be most appropriate in this group of patients? Second, how often should CGM be employed (all the time, when there is a change in drugs or intermittently for troubleshooting)? Third, should it be limited to insulin and sulfonylurea users, which carry a higher risk of hypoglycaemia? Finally, it would be important to identify facilitators and barriers to CGM use in older people with memory problems, with specific focus on factors such as dementia severity, functional status, availability of carers, familiarity with self-monitoring and so on that can influence data capture.

There is a clear need for a large-scale prospective study using CGM to assess its true potential impact in this vulnerable group. CGM would be used to capture hypoglycaemic episodes and guide the hypoglycaemia minimisation strategy. In addition, CGM may be a useful and supportive tool for carers in their day to day care of this vulnerable group of older people, especially those on insulin. Further work is needed to explore whether older people with memory problems will be able to deal with the technology for continuous Bluetooth capture and reacting to the data that is produced by the software, including alarms for high and low glucose levels.

\section{CONCLUSION AND IMPLICATIONS}

It is potentially feasible for older people with diabetes and memory problems to operate a CGM device that requires users to conduct intermittent scans. However, the added benefit of real-time transmission CGM devices that do not require active scanning needs to be explored further in this group of patients.

Acknowledgements We thank all of the participants who took part in this study. We also thank Mr Paul Millac and Mr Dick Abbott for their assistance and support as Alzheimer's Society Research Network Volunteers.

Contributors Conception and design: KM YKL, CS, KL, KD, SN, HMM. Data acquisition: KM, KL, YKL Analysis and interpretation of data: YKL, KM, KL, KD, CS.
Drafting, revision and final approval of the manuscript: KM, YKL, CS, KL, KD, SN, HMM. YKL is the guarantor.

Funding KM is funded through a clinical training fellowship from the Alzheimer's Society (Grant number: 324) with support from McKesson.

Disclaimer Neither the funder nor McKesson had a role in the design of the study or the interpretation of the findings.

Competing interests All authors have completed the ICMJE uniform disclosure form at www.icmje.org/coi_disclosure.pdf and declare no support from any organisation for the submitted work beyond the Alzheimer's Society grant. YKL reports personal fees from Thame Pharmaceuticals.

Patient and public involvement The study was supported by two lay members of the Alzheimer's Society Research Network which provided input to the feasibility study. They were members of the Trial Steering Committee which met on a regular basis. They partnered with us for the design of the study, the production of the patient information leaflet and provided invaluable insight into complexities of being a carer for an older person with diabetes and dementia. At the end of the study, the lay members commented on the findings and contributed to the dissemination plan.

Patient consent for publication Not required.

Ethical approval The study was approved by the East of England-Cambridge Central Research Ethics Committee (reference 17/EE/0388). The trial registration ID is ISRCTN29516623.

Provenance and peer review Not commissioned; externally peer reviewed.

Data availability statement All data relevant to the study are included in the article or uploaded as supplementary information.

Open access This is an open access article distributed in accordance with the Creative Commons Attribution Non Commercial (CC BY-NC 4.0) license, which permits others to distribute, remix, adapt, build upon this work non-commercially, and license their derivative works on different terms, provided the original work is properly cited, appropriate credit is given, any changes made indicated, and the use is non-commercial. See: http://creativecommons.org/licenses/by-nc/4.0/.

ORCID iD

Katharina Mattishent http://orcid.org/0000-0002-7577-0689

\section{REFERENCES}

1 Bunn F, Burn A-M, Goodman C, et al. Comorbidity and dementia: a scoping review of the literature. BMC Med 2014;12:192.

2 International Diabetes Federation. IDF diabetes atlas, 2017. Available: http://www.diabetesatlas.org

3 Alzheimer's Disease International. World Alzheimer report 2018, 2018. Available: https://www.alz.co.uk/research/WorldAlzheimerRe port2018.pdf

4 Harsch IA, Kaestner RH, Konturek PC. Hypoglycemic side effects of sulfonylureas and repaglinide in ageing patients - knowledge and self-management. J Physiol Pharmacol 2018;69. doi:10.26402/ jpp.2018.4.15. [Epub ahead of print: 09 Dec 2018].

5 Hambling CE, Seidu SI, Davies MJ, et al. Older people with type 2 diabetes, including those with chronic kidney disease or dementia, are commonly overtreated with sulfonylurea or insulin therapies. Diabet Med 2017;34:1219-27.

6 Mattishent K, Loke YK. Meta-Analysis: association between hypoglycaemia and serious adverse events in older patients. $J$ Diabetes Complications 2016;30:811-8.

7 Mattishent K, Loke YK. Bi-Directional interaction between hypoglycaemia and cognitive impairment in elderly patients treated with glucose-lowering agents: a systematic review and metaanalysis. Diabetes Obes Metab 2016;18:135-41.

8 Prinz N, Stingl J, Dapp A, et al. High rate of hypoglycemia in 6770 type 2 diabetes patients with comorbid dementia: a multicenter cohort study on 215,932 patients from the German/Austrian diabetes registry. Diabetes Res Clin Pract 2016;112:73-81.

9 Mattishent K, Loke YK. Detection of asymptomatic drug-induced hypoglycemia using continuous glucose monitoring in older people systematic review. J Diabetes Complications 2018;32:805-12.

10 Hodkinson HM. Evaluation of a mental test score for assessment of mental impairment in the elderly. Age Ageing 1972;1:233-8.

11 Jackson TA, Naqvi SH, Sheehan B. Screening for dementia in general Hospital inpatients: a systematic review and meta-analysis of available instruments. Age Ageing 2013;42:689-95. 
12 Wright LA-C, Hirsch IB. Metrics beyond hemoglobin A1c in diabetes management: time in range, hypoglycemia, and other parameters. Diabetes Technol Ther 2017;19:S-16-S-26.

13 Battelino T, Danne T, Bergenstal RM, et al. Clinical targets for continuous glucose monitoring data interpretation: recommendations from the International consensus on time in range. Diabetes Care 2019;42:1593-603.

14 Braun V, Clarke V. Using thematic analysis in psychology. Qual Res Psychol 2006;3:77-101.

15 Neugroschl J, Sano M, Luo X. Why they stay: understanding research participant retention in studies of aging, cognitive impairment and dementia. J Gerontol Geriatr Res 2014;03.

16 Ruedy KJ, Parkin CG, Riddlesworth TD, et al. Continuous glucose monitoring in older adults with type 1 and type 2 diabetes using multiple daily injections of insulin: results from the diamond trial. $J$ Diabetes Sci Technol 2017;1932296817704445.

17 Beck RW, Riddlesworth T, Ruedy K, et al. Effect of continuous glucose monitoring on glycemic control in adults with type 1 diabetes using insulin injections. JAMA 2017;317:371-8.
18 Alitta Q, Grino M, Adjemout L, et al. Overestimation of hypoglycemia diagnosis by FreeStyle Libre continuous glucose monitoring in long-term care home residents with diabetes. J Diabetes Sci Technol 2018;12:727-8.

19 Carlson AL, Kanapka L, Miller K. Exposure to Hypoglycemia in Older Adults with Type 1 Diabetes: Baseline Characteristics Using Continuous Glucose Monitoring Data. Endo 2019; 23-26 March 2019, New Orleans, LA, 2019.

20 Woodford HJ, George J. Cognitive assessment in the elderly: a review of clinical methods. QJM 2007;100:469-84.

21 Soma Y, Oka R, Fujii S, et al. [The status of glycemic control and hypoglycemia in elderly patients visiting the outpatient department specializing in diabetes]. Nihon Ronen Igakkai Zasshi 2018;55:268-75.

22 NHS. The NHS Long Term Plan [updated 21 August 2019], 2019. Available: https://www.longtermplan.nhs.uk/wp-content/uploads/ 2019/08/nhs-long-term-plan-version-1.2.pdf 